\title{
И.А. Бабаскина
}

Алтайский государственный университет

\section{Гипертекстовый перфект с позиций функциональной грамматики}

Аннотащия: В центре внимания автора статьи находится исследование функционирования грамматической категории перфекта в многомерном электронном гипертексте. Грамматическая категория временной отнесенности (таксиса) организует «безвременные и бесконечные» гипертекстовые потоки в развертывающуюся последовательность происходящего здесь-и-теперь. Органическая связь и взаимодействие перфекта с категориями темпоральности и вида, обуславливает семантическую и композиционно-стилистическую емкость данной грамматической категории. Закономерным следствием этих языковых фактов является способность английских перфектных форм обеспечить линейную связь между текстовыми фрагментами, характерную для гипертекста с его ризоморфной структурой, и тем самым исполнять роль прикладного руководства поведением Человека, обживающего информационное пространство.

This article is devoted to the research of functioning of the perfect tense in multidimensional electronic hypertext. The grammatical category of taxis turns each time flow into developed sequence of occurring here-and-now. Integral relation and interaction between Perfect and grammatical categories of aspect and time defines semantic and stylistic content of Perfect. The regular consequence of these language facts is the ability of the English Perfect forms to establish linear links between the text fragments, thus carrying out the role of an applied guide to human behaviour in the information-oriented society.

Ключевые слова: функциональная грамматика, электронный гипертекст, ризома, временной поток, таксис, гипертекстовый перфект, структурно-функциональный анализ, темпоральное значение, аспектуальное значение.

Functional grammar, the electronic hypertext, rhizome, a time flow, taxis, Hypertext Perfect, structure functional analysis, temporal meaning, aspect meaning.

УДК: 81-116.3.

Контактная информация: Барнаул, ул. Димитрова, 66. АлтГУ, филологический факультет. Тел. (3852) 243974. E-mail: irina_asu@mail.ru.

Появление глобальной сети коренным образом меняет способ построения текстового пространства - на смену одномерному тексту приходит многомерный электронный гипертекст, что влияет и на функционирование грамматических категорий.

Грамматическая категория перфекта определяется самой гипертекстовой реальностью и отражает ее конкретные характеристики, к которым относятся, прежде всего, время и пространство. Перфект является нулевой точкой пространственно-временных координат того, к чему мы обращаемся как к дейктическому контексту. Дейксис гипертекстовой ситуации определяется понятиями here «здесь» и now «сейчас»; использование этих средств обусловлено объективно, 
и Интернет-пользователь не выбирает перфект, а использует их «по принуждению» гипертекстовой реальности.

В ходе нашего исследования были выделены основные функции английского «гипертекстового» перфекта, с помощью которых «безвременные и бесконечные» гипертекстовые потоки преобразуются в развертывающуюся последовательность происходящего здесь-и-теперь.

Понятие функции является центральным для структурно-функционального анализа и рассматривается нами в двух аспектах: 1) как «назначение» или «роль» грамматической категории перфекта по отношению к гипертекстовой системе в целом; 2) как «такая зависимость» в рамках данной целостности (системы), при которой изменение перфекта оказываются производными (функцией) от изменений гипертекста. В этом (втором) случае вводится понятие функциональных связей внутри гипертекстовой системы, а также между гипертекстовой системой и электронной средой. Соответственно выделяются и процессы функционирования (поддержания организации-организованности, порядка) наряду с процессами производства (ресурсов-перфекта), воспроизводства (структуры гипертекста), в совокупности обеспечивающие стабильное существование гипертекстовой системы (целостности) и соотносимые с процессами ее изменения и развития (как в результате естественной эволюции, так и вследствие специально предпринимаемых («искусственных») усилий [Новейший философский словарь, 2003, с. 997].

В данном исследовании применяется функциональный подход, в соответствии с которым функции перфекта выделяются на разных основаниях, в зависимости от того, какой из компонентов комплексной семантики перфекта выходит на первый план.

Универсальный перфект (Universal Perfect), сочетая в себе темпоральные, таксисные и аспектуальные функции, исполняет роль нулевого грамматического времени в гипертекстовом пространстве, поскольку именно данная грамматическая форма способна расположить гипертекстовые события относительно точки отсчета (the reference point) [Alexiadou, 2003] и организовать каждый временной поток в развертывающуюся последовательность здесь-и-теперь.

(1) e.g. The programme has been running a term and a half, so it's still a work in progress, but he is confident about its prospects, saying that it gives PSHE (commonly known as "citizenship" lessons) a more distinctive framework [Kneen, 2004].

Форма Present Perfect Continuous в примере (1) (has been running), подчеркивая процессуальность, «вписывает» вполне конкретное действие в некий динамичный контекст [Веселкова, 2002]. События, упорядоченные отношением «раньше, чем» (a term and a half) - «позже, чем» (but he is confident about its prospects), организуются во временные последовательности относительно пространственновременного центра «здесь-и-теперь» (it's still a work in progress). Таким образом, границы события, выраженного Универсальным перфектом, размываются, включая некоторое время «до», и отбрасывая тень на будущее. Значение будущего, включенное в момент объективного настоящего «здесь-и-теперь». Перфектная длительность или процессуальность дает жизнь временной непрерывности и целостности жизни в гипертекстовом пространстве. Длительное действие по большей части выражается перфектом, когда указано количество времени, в течение которого оно продолжалось, - определенное какой-либо мерой, например: «a term and $a$ half» (пример (1)).

Рассмотрим два других примера Универсального перфекта, с помощью которых устанавливается пространственно-временная очередность событий, описанных в новостной статье «Нарру Talk» на британском сайте «the Observer Guardian»». 
(2) e.g. Since then, there has been a rising clamour for more happiness, or less unhappiness, most recently with Oliver James's book Affluenza, which identifies mass consumerism as the root of our malaise [Kneen, 2004].

(3) e.g. British happiness levels have been static since the Seventies, which mirrors the experience of most developed countries [Ibid., 2004].

В примере (2) и (3) форма Универсального перфекта since then, there has been a rising clamour; happiness levels have been static since the Seventies описывает события как предшествующие точке отсчета и одновременно продолжающиеся «здесь-и-теперь» (ongoing), тем самым, совпадая с описанием перфекта Рейхенбаха одновременно как предшествующее прошедшее (Priorian past) и «растянутое» (длительное) настоящее (Extended Now) (which mirrors the experience of most developed countries) [Reichenbach, 1947]. П. Потнер трактует действие, выраженное формой Универсального перфекта, как продолженное перфектное (continuative perfect) [Portner, 2000].

Универсальный английский перфект, в свою очередь, имеет грамматическую форму Present Perfect Simple или Present Perfect Continuous и не употребляется в I лице. В силу широты своей семантики в момент текущего (длительного) «здесьи-теперь» (ongoing) включает моменты «предшествующего» и «последующего». Назначение Универсального перфекта в гипертекстовой среде - использование всей совокупности воспринимаемого «здесь-и-теперь» в качестве исходного материала для построения пространственно-временной последовательности. Следовательно, перфект есть грамматическая категория пространственно-временной очередности или последовательности (the grammatical category of Order) [Valeika, Buitkiené, 2003]. Отсюда можно выделить организующую функцию перфекта, с помощью которой временной поток электронного гипертекста преобразуется во временную последовательность.

Органическая связь и взаимодействие перфекта с категориями темпоральности и вида, обуславливает семантическую и стилистическую емкость данной грамматической категории. Закономерным следствием этих языковых фактов является широкая возможность функциональных транспозиций перфектных форм, их метафорического использования. Следовательно, познавательное содержание перфектных форм не может быть полностью раскрыто без анализа их экспрессивно-аффективного аспекта, без той коннотативной информации, которую может передать грамматическая форма.

Стилистическое использование перфектных форм до сих пор мало изучено, однако, для адекватного восприятия этих форм в тексте чрезвычайно важно точное определение грамматического значения и стилистических функций перфектных форм. И.В. Докучаева выделяет две группы «стилистического» употребления перфектных форм: 1) эмфатическое употребление и 2) композиционно-стилистическое употребление.

Остановить внимание читателя на каком-то из многочисленных событий в потоке гипертекстовых событий позволяет перфект, который, как считает С.Н. Плотникова, является стилистически окрашенной формой, способной обратить некоторые события, как в примерах 4 и 5 (have recovered 195 bodies; have already been charged) в «яркие и выпуклые», в то время как форма простого прошедшего оказывается нейтральной: were rescued, remained, identified [Грицюк, 2005 , c. 165].

(4) Video Police said more survivors were rescued from the Egyptian ferry which caught fire and sank, but about 700 people remained missing and search teams have recovered 195 bodies [Nasrawi, 2006].

(5) Following the shooting, detectives identified three chief suspects, two of whom have already been charged with murder [Ibid., 2006]. 
Потоки информации, которые изливаются на интернет-серфера, путешествующего по глобальной сети, не контролируются по причине децентрированности и неиерархичности устройства, именуемого Интернет, унаследовавшего подобные признаки от своего прообраза - ризомы.

Жиль Делез и Феликс Гваттари в небольшой работе под заглавием «Ризома» манифестируют ризоматический смысл как умение перемещать себя, начиная с середины, умение двигаться между вещей и выстраивать маршрут при помощи проводимых линий, а не точек [Делез, 1976].

Переводя понятия «линии» и «точки», действующие в гипертекстовом формате, на язык грамматики, попробуем доказать, что грамматическое значение и композиционно-стилистические функции английских перфектных форм способны обеспечить линейную связь между текстовыми фрагментами, характерную для гипертекста с его ризоморфной структурой. Автор книги «A new approach to English tense» Tang Shun в одном из разделов третьей главы « $\underline{\text { Only can Simple Past }}$ link up a series of actions» говорит о свойственной только форме простого прошедшего возможности передачи информации о нескольких событиях, случающихся последовательно, сразу друг за другом на каком-то определенном отрезке в прошлом [Tang Shun, 2005], например: (6) Overton said tracking also allowed bosses to check whether workers were taking the quickest route to a job or whether the expenses they submitted matched the miles they had drive [Jones, 2006].

Такую связь между событиями (выделенными в примере) можно определить как точечную, так как форма простого прошедшего (аориста) не способна совершить прыжок в предпрошедшее или установить связи между событиями прошлого и настоящего, переплетая далеко стоящие друг от друга в пространственном и хронологическом плане действия. В таком грамматическом значении форма аориста противопоставляется перфектной форме в рамках свойственных ей проспективной и ретроспективной функций. Благодаря проспективной или, как определяет ее М.А. Грицюк, результативной функции, действия в перфектной форме предвосхищает, предопределяет последующие действия и, заинтересовывая читателя, заостряет его внимание на причине и ходе разворачивающихся событий, приводящих к тому или иному результату или исходу, как в примерах 7 и 8 (could save an average of $£ 100$ a year; there will be none at all), а также подчеркивает значимость полученного результата [Грицюк, 2005, с. 162].

(7) According to the energy minister, Malcolm Wicks, those who have already considered switching suppliers (as a result) could save an average of $£ 100$ a year [Kneen, 2004].

(8) "The problem started from two generations back. A lot of the parents have grown up in an era where there was a lack of respect. It's totally gone once it has got to their children. Eventually there will be none at all," says 50-year-old Ken [Ibid., 2004].

Перфект прошедшего времени широко используется в ретроспективной функции, связывая действия «предпрошедшего» и прошлого, он демонстрирует непрерывный временной поток [Грицюк, 2005, с. 164], что позволяет пользователю глобальной сети целиком и полностью перенестись в иную плоскость, где создается своя линейная последовательность описываемых действий, например: (9) Police said the three men, all aged 24, who were arrested on Wednesday had now been charged with conspiracy to commit robbery at the travel agency... A 32-year-old man who had also been arrested was released without charge [Nasrawi, 2006].

Проанализировав композиционно-стилистический потенциал гипертекстового перфекта и то общее, что связывает проспективную и ретроспективную функции перфектных форм воедино, можно выделить вторую функцию - соединительную или связующую [Грицюк, 2005, с. 164]. 
В такой функции форма английского перфекта выступает в роли определенного правила или кода, который устанавливает линейные переходы между текстами, позволяя пользователю гипертекстовой информации преодолеть принцип разветвленности, амбивалентности и сверхдетерминации, путем построения определенного маршрута движения по ризомоподобной системе, именуемой Интернетом. Таким образом, перфектные формы, соединяя стоящие рядом и значительно отдаленные текстовые сегменты, участвуют в когерентности текста [Докучаева, 1977, с. 28] Сходным образом перфектная форма может выразить причинность, обусловленность предшествующего действия последующим, логическую связь между действиями, формируя ткань повествования [Грицюк, 2005, с. 164].

Подводя итог, нельзя не сказать, что ни одна из выделенных функций не реализуется в гипертексте изолированно. Как правило, функции перекрещиваются, накладываются друг на друга, создавая единый комплексный композиционно-стилистический эффект.

Функционально за английским перфектом закреплена роль своего рода «сигнальной ракеты», которая запускается в безвременном пространстве гипертекста и служит отправной точкой для дальнейшего развития повествования в гипертексте. В этом смысле английский перфект может восприниматься как предикат - нарушитель спокойствия, перекраивающий информационное пространство высказывания в угоду (в помощь) читающему [Корчажкина, 2004].

\section{Литература}

Веселкова Н.В. Глобальное и локальное в социальном времени: фрагментация или сохранение целостности? 2002. [Электронный ресурс]. Режим доступа: www.chronos.msu.ru.

Грицюк М.А. Стилистический потенциал перфекта настоящего и прошедшего времени в английском языке. // Материалы шестой научной конференции. Новосибирск, 2005.

Делез Ж., Гваттари Ф. Ризома // Капитализм и шизофрения. Перевод и предисловие В. Мерлина (Gilles Deleuze and Felix Guattari, Capitalism and Schizophrenia). 1976. [Электронный pecypc]. Режим доступа: http://kprpfo.chat.ru/nom.html.

Докучаева И.В. Употребление глагольных форм Perfect и Perfect Continuous в новоанглийском языке XVIII XX вв. // Сборник научных трудов. М., 1977. Вып. 110: Вопросы грамматики английского языка.

Корчажкина О.М. Три «прорыва» в понимании английского перфекта: ретроспективный взгляд // Цикл статей «Этот многоликий английский перфект». Издательский дом «Первое сентября» 2004 г. [Электронный ресурс]. Режим доступа: http:festival.1september.ru.

Новейший философский словарь / Под ред. А.А. Грицанова. Минск, 2003.

Alexiadou A., Rathert M., and Arnim von Stechow Introduction: the modules of Perfect constructions. Berlin: Mouton de Gruyter. 2003. [Электронный ресурс]. Peжим доступа: http://2.sfs.uni-tuebingen.de/ arnim10/Aufsaetze/vorwortperfect.pdf

Jones M. Firms turn cyber sleuths with cell phone technology. 05.02.2006. [Электронный ресурс]. Режим доступа: www.guardian.co.uk.

Kneen J. Happy Talk. 30.11.2004. [Электронный ресурс]. Режим доступа: www.guardian.co.uk.

Nasrawi S. Three charged by PC murder hunt detectives. 05.02.2006. [Электронный ресурс]. Режим доступа: www.newsbox.msn.co.uk.

Portner P. The (Temporal) Semantics and (Modal) Pragmatics of the Perfect. Georgetown University. 2000. [Электронный pecypc]. Режим доступа: http://semanticsarchive.net/Archive/2MxZjI3M/Portner-perfect.pdf.

Reichenbach H. Elements of Symbolic Logic, London: Collier. MacMillan. 1947. [Электронный ресурс]. Режим доступа: www.lingref.com 
Tang Shun A new approach to English tense. Published by Mercury Consultants Limited. 2005. [Электронный ресурс]. Режим доступа: http://englishtense.com

Valeika L., Buitkienė J. Absolute and Relative Tenses // An Introductory Course in Theoretical English Grammar. Vilnius Pedagogical University. 2003. 